\title{
Benrthellung der Frage, ob das Ozon in der Luft existiren könne oder nicht.
}

In der Sitzung der Akademie der Wissenschaften vom 27. November des verflossenen Jahres hat Frémy einen Vortrag gehalten, welcher sehr die Ursache des atmosphärischen Ozons compromittirt. „Man glaubt, sagt er, dass das Ozon eins von den Elementon der Luft sei, und man ist selbst so weit gegangen, zu behaupten, dass eine Abwesenheit von Ozon die Ursache gewisser Epidemien sei."

Ich bin weit davon entfernt, die Untersuchungen, welche in jüngster Zeit über das Ozon angestellt sind, zu verdächtigen, nur eine Frage, welche eine der wichtigsten ist, die die Chemie behandeln kann, möchte ich an Diejenigen richten, welche sich mit Ozonometrie beschäftigen, die Frage nëmlich, ob der Augenblick nicht gekommen sei, die ozonometrischen Methoden, welche sie gebrauchen, streng wissenschaftlich zur Discussion zu bringen.

Wenn davon die Rede ist, die Menge eines Körpers kennen zu lernen, welchen man als einen der Elemente der Luft betrachtet und denselben eine Rolle in den physiologischen Fragen spielen lässt, dann müssen die Methoden der Untersuchung streng und genau sein.

Ohne nun die Wichtigkeit der Anzeichen zu verkennen, welche durch das Papier von Schönbein oder das von Hou zea u erhalten werden, so fand ich doch nicht, dass diese Reactionen mit vollständiger Sicherheit das Vorhandensein des atmosphärischen Ozons anzeigen.

Man ist noch sehr weit davon entfernt, alle Körper, welche sich in der Luft suspendirt finden, und die Wirkung, welche sie auf Jodkalium ausüben, zu kennen.

Es ist die Frage, ob dieses Salz nicht auch unter anderr Einflüssen als dis des Ozon's alkalisch werden oder Jod entwickeln könne. Ich kenne nur eine einzige Probe, wodurch man genau die Anwesenheit des Ozons in der Luft anzeigen kann, und diese besteht darin, dass man das Silber oxydirt, indem man feuchte Luft auf dieses Metall einwirken lässt. Ich fordere dringend die Vertreter der atmosphärischen Ozonometrie auf, diese Versucho zur Ausführung zu bringen. Ich habe sie wiederholt geprüft, doch stets ohne Erfolg. Ich bin also der Ansicht, dass die Gegenwart des Ozons in der Luft aufs Neue durch unumstössliche Versuche festgestellt werden muss. Ich verkenne die Thatsache nicht, ich wünsche aber eine positive Probe; der experimentelle Beweis scheint mir zu 
nothwendig zu sein, denn, wenn man die Eigenschaften des Ozons kennt, wenn man weiss, dass es durch organische Substanzen unmittelbar vernichtet und vom Stickstoff absorbirt wird, so kann man ziemlich schwierig annehmen, dass ein solcher Körper in der Luft besteht, der gerade die Elemente enthält, welche das Ozon anzeigen können.

Ehe man einige Folgerungen hinsichtlich der Farbenveränderungen, welche ein ozonometrisches Papier in der Luft erleidet, macht, ist es nützlich zu untersuchen, ob das Reagens für genaue Bestimmungen dienen kann. Es scheint mir ebenso nöthig zu sein, die wesentliche Ursache der Farbenveränderung, welche das ozonometrische Papier erleidet, kennen zu lernen, denn welchen Nutzen kann ein Reagens besitzen, welches nicht allein durch Ozon angezeigt wird, sondern auch durch verschiedene Substanzen, welche in der Luft suspendirt sind?

Houzeau hat vor der Société chimique zu Paris erklärt, dass er sehr gern an erkennt, wie der Beweis für die Existenz des Ozons in der Atmosphäre noch nicht geliefert sei, und dass es sehr schwierig sei, diese durch eine directe Probe zu liefern. (L'art médical et Journal de Pharmacie d'Anvers. Mai 1866.).

Dr. Joh. Müller.

\section{Ueber das Maximum der Dlchtigkeit des destillirten Wassers und uber die Dilatation desselben}

hat F. Rosetti, Prof, an der Universität zu Padua auf Regnault's Veranlassung Versuche angestellt, deren Resultate ihm als Ausgangspunkt für weitere Untersuchungen über die Ausdehnung ron Salzlösungen dienen sollten, welche wichtige Frage bis jetzt nur wenig berïcksichtigt worden ist. Alle unsere Kenntnisse über dieselbe lassen sich in folgende Sätze zusammenfassen, welche Despretz aus seinen zahlreichen Untersuchungen resumirt:

1) Das Meerwasser und allo wässrigen Lösungen haben ein Dichtigkeitsmaximum.

2) Dieses Maximum sinkt rascher als der Gefrierpunkt.

3) Die Erniedrigung des Gefrierpunkts unter Null und diejenige des Dichtigkeitsmaximums unter $+4^{\circ} \mathrm{Cels}$. sind genau proportional den Mengen fremder Stoffe im Wasser.

Das letzte Gesetz ist eigentlich von Despretz nur vorausgesehen worden, und der Beweis desselben bleibt noch zu führen. 